\title{
The Application and Practice of the Voltage Reactive Power Optimization Automatic Control System (AVC) in the Power Grid of Wuhu Region
}

\author{
Sun Liang ${ }^{1, *}$, Jian Xusheng ${ }^{1}$, Yuan Wenqiang ${ }^{1}$ and Song $\mathrm{Li}^{2}$ \\ ${ }^{I}$ Electrical Engineering College of Northeast Dianli University, Jilin City, 132012, China \\ ${ }^{2}$ State Grid Liao Ning Liao Yang Electric Power Supply Company Liao Ning, China
}

\begin{abstract}
In the paper, the influence of harmonic was taken into consideration during the realization of the AVC system in the power grid of Wuhu region, relevant study and development were conducted from the perspective of application and practice, and concrete proposal of practicable reactive voltage power optimization was put forward. The system adopted two-layer control plan: whole-network coordination layer and execution layer within transformer substation. Optimization algorithm adopted the reactive power optimization method with relaxed constraints so as to improve the convergence and computation speed of reactive power optimization. To control the impact of harmonic, a hybrid active power filter scheme which was made up of passive power filter and active power filter was adopted, thus improving the cost performance of the AVC system. The result of applying the AVC system in the power grid of Wuhu region shows that the system is stable and reliable, obviously decreasing the operation times of equipment and improving the voltage qualified rate and power factor of panel point.
\end{abstract}

Keyword: AVC, Reactive Power, Adaptive Control, SCADA, Harmonic Wave.

\section{INTRODUCTION}

In the power grid, frequency and voltage are the two major indicators of power quality. AGC lays particular emphasis on frequency control, while AVC focuses on voltage control. The voltage reactive power optimization of the whole network is the core and foundation of the implementation of AVC system, therefore the voltage reactive optimization in $\mathrm{AVC}$ has a higher requirement on computation speed and robustness. The AVC system is a distributed control system, namely the hierarchy control of centralized decision, and SCADA is its core data processing and control system.

Currently, unreasonable distribution of reactive power flow and unreasonable distribution of reactive power in large generator units are outstanding problems in the power grid of most regions in China. The complexity of the power system continuously improved with the rapid expansion of the size of regional power system and the structural system of interconnected power grid, which made the original pattern of only setting automatic control equipment of reactive power and voltage in transformer substation difficult to realize economic operation of power grid. For single transformer substation in regional power grid, the compensating partial adjustment of locally improving the voltage qualified rate and power factor without entire-network reactive power optimization will easily lead to the deterioration of the operation of superior power grid and at the same time, it may also result in the frequent adjustment of voltage and reactive power in on-load voltage regulation of power grid, thus more easily leading to unreasonable voltage regulation and reactive power flow. Therefore, voltage reactive power optimization should take comprehensive control for the whole power grid so as to achieve the optimum of whole power grid, improve the voltage level of each node and reduce the network loss [1-3].

The reactive power dispatch of the power grid in Wuhu region has the following outstanding problems: insufficient reactive power compensation during the peak load and unqualified voltage quality caused by surplus reactive power during the low load. Besides, the VQC device belongs to single substation adjustment, thus its influence on system operation can not be taken into overall consideration and it is also hard to achieve the optimization result of the integrated control of voltage reactive power. Therefore the VQC device can't timely reduce the active loss brought by the unreasonable reactive current. For example, the survey of Li Duanchao on the power grid of Anhui province [4].

\section{DESIGN OF THE AVC SYSTEM OF THE WUHU POWER GRID}

\subsection{System Structure}

The control system was divided into two layers: the coordination layer of entire network (control center) and the executive layer within each substation. The hierarchy of control system was mixed mode. At present, some developed countries in Europe generally adopt three-level organization 


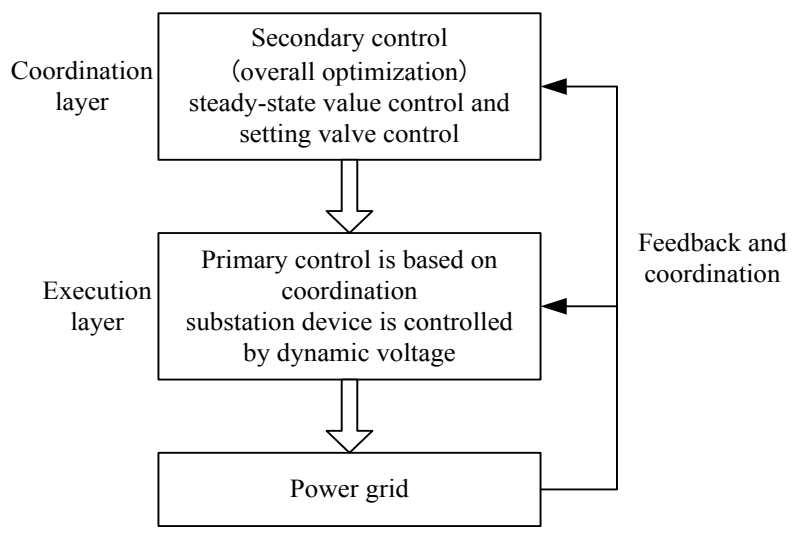

Fig. (1). Logical layering mode.

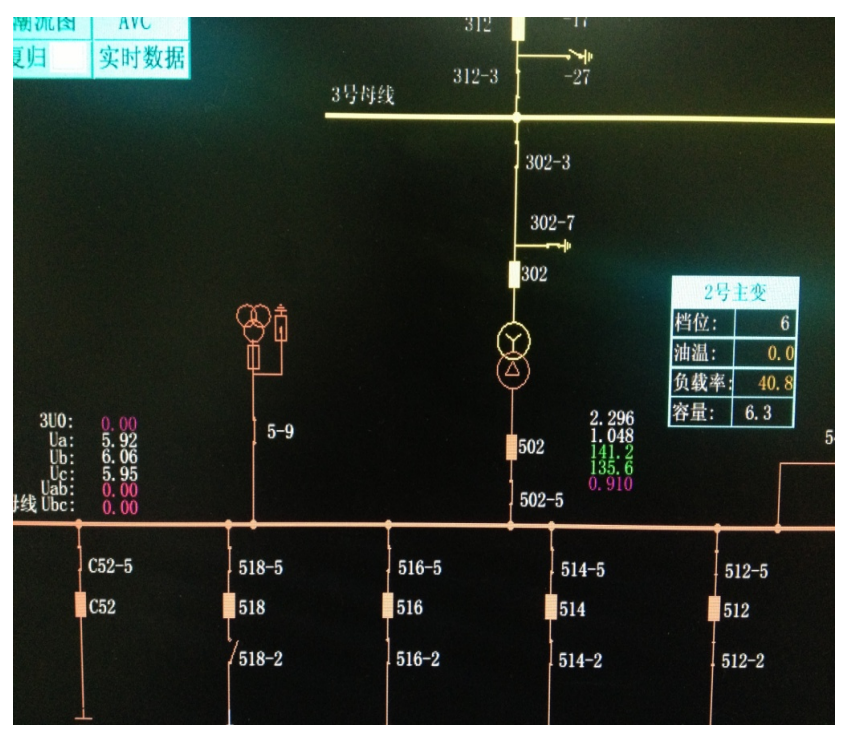

Fig. (2). Yi jiang district reactive voltage optimization of automatic control system (AVC) main interface.

pattern. This kind of hierarchical and partitioning voltage control strategy has been practiced and run for many years by many countries, such as France and Italy, with satisfactory results [5]. The optimization and transformation of the power grid in Anhui also have taken this model [4], as shown in Fig. (1).

Main station coordination layer and substation VQC are controlled by a decentralized coordinate system, which belongs to a kind of physical layering. The transformer substation without VQC device is controlled by a kind of logical layering, namely centralized control which is collectively controlled by the main station coordination layer, logic control layer and telecontrol layer [6].

The main interface diagram of reactive voltage optimization automatic control system (AVC) of the power grid in Wuhu region (the Yiriver district does not match the actual as the substation is not corresponding) is as shown in Fig. (2). As shown in the figure, there are ten $110 \mathrm{kv}$ substations with respective AQC system. The AVC system involved in the study was implemented in the $220 \mathrm{kv}$ master station, and was connected with the AQC system of each $110 \mathrm{kv}$ substation through the net network.

\subsection{The Target and Function of the AVC System}

Establish entire network model in the entire network coordination layer. When the power grid is functioning normally, the AVC system, based on real-time data, conducts reactive power optimization calculation and minimum operation under emergency for the ultimate purpose of minimum network loss to recover the voltage into the normal two objective functions, and thus determining the voltage and interest rate setting value of each node.

Under physical layering mode, the VQC system of each substation in the power grid automatically adjusts the switch of on-load tap changing transformer tapping, capacitor bank or electric reactor according to the AVC given value. When an exception occurs, the VQC system of each substation will independently complete its own voltage quality control based on the decentralized control principle determined by system function and deal with the emergency.

Under logical layering mode, the system implements dynamic monitoring on running status of power grid according to the optimization constraints given by optimizing calculation and on the basis of expert protocol and fuzzy logic rules 
agreed by the system, and directly give instruction to the telecontrol equipment of each substation to carry out scheduling operation. Coordination layer and power grid, executing/monitoring layer and power grid both form two-layer closed-loop control structure. When executives layer (VQC device) is out of service due to fault, the reactive voltage control of corresponding substation will be artificially changed to centralized control mode [7].

\subsection{Reactive Power Optimization Algorithm}

Reactive power optimization of power system refers to the process of finding the operation mode which can make one or more performance indicator of the system optimized and meet all constraints through some control variables determined by optimization calculation in the system with given active load, power supply, current and network structure .In other words, it is the reactive power distribution scheme that can make one or more performance indicator of the system optimized under the premise of satisfying the needs of system loading and operation constraints [8].

In 1962, the French scholar J. Carpentier firstly put forward the economic operation mode based on strict mathematical foundation, including the constraint conditions like voltage. The model came to be known as the optimal power flow (OPF) problem. Classic algorithms of reactive power optimization starts from an initial point, continues to improve the current solution according to certain track, and eventually converges to the optimal solution.

Considering the circumstance that there are many lowvoltage lines in Wuhu region, it is difficult to fully meet the condition of $\mathrm{R}<<\mathrm{X}$. Therefore it is suitable to use reactive power optimization method of optimal power flow with relaxed constraints instead of ordinary active and reactive power decoupling algorithm, so that the convergence and computation speed of reactive power optimization can be improved [9]. This power flow algorithm is based on the Newton power flow algorithm which belongs to secondorder term, and as long as the network structure remains the same, there is no need to modify the Jacobian matrix. The Newton power flow algorithm has high calculation accuracy and convergence, and it can greatly improve the computing speed of the system.

To reduce the active loss as much as possible, real-time reactive power optimization control requires expense of acceptable operation times and regulating variable of reactive power regulating equipment, which requires to give consideration to both safety and economy of the system operation, and enable the system to have certain ability to withstand load fluctuation [10].

\subsubsection{Objective Function Under Two Operation Mode}

(1) Objective function under ordinary operation mode

The active loss of the transmission line can be expressed as:

PLoss $=K \frac{P^{2} L}{U^{2} \cos \varphi}$
Then, the mathematical model under ordinary operation mode is:

o. b. $\operatorname{Min} F=\sum P_{\text {LosS }}$

In the equation: $P$ is the active power of line transmission; $U$ is the line voltage; $L$ is line length; $\cos \phi$ is power factor. If the voltage is at high level, the line loss $P_{\text {Loss }}$ will decrease when transmitting certain power $P$ As the loss is in inverse proportion to the squared value of voltage, the voltage can be raised by decreasing the reactive power flowing in the line, thus decreasing line loss.

(2) The mathematical model under operation in fault:

$\operatorname{Min} f(x)=\sum_{i} \omega_{i} c_{i}\left(\triangle X_{i}\right)$

In the equation: $\operatorname{ci}(\Delta X i)$ represents the expense of optimally controlling $X i$ to diverging its initial value or rated value. The multiplier $\omega$ is a deviation weighting factor(default value $=1$ ) provided by user and it is used to assign the influence of each control variable on objective function.

\subsubsection{The Control Variables and Constraints of Reactive Power Optimization}

According to the requirements of design scheme, the control variables of reactive power optimization include three variables: switch of multipled capacitor (electric reactor) group, voltage amplitude of generator node and tap voltage/reactive power control of on-load voltage regulator and transformer. To ensure power grid security and extend the service life of equipment, necessary system operation constraints should be added, namely the continuous tap changing times and daily regulation changing times of transformer tap; interval time and daily tap changing times of capacitor switching; synchronous adjustment of paralleling transformer tap. As shown in the following equations:

$$
\begin{aligned}
& g(x, u)=0 \\
& Q_{g \text { min }} \leqslant Q_{g} \leqslant Q_{g \text { max }} \\
& V_{D_{\text {min }}} \leqslant V_{D} \leqslant V_{D_{\text {max }}} \\
& V_{g_{\text {min }}} \leqslant V_{g} \leqslant V_{g \text { max }} \\
& T \phi_{\text {min }} \leqslant T \phi \leqslant T \phi_{\text {max }} \\
& 0 \leqslant Q_{c} \leqslant Q_{c \text { max }}
\end{aligned}
$$

In the equation: $x$ is the state variable vector, $u$ is the control variable vector. The equation respectively represents the operating limit of load busbar and generator and the scope of control variable.

In the equation: $Q_{c}$ and $Q_{c m a x}$ respectively are the capacity and limit of adjustable capacitor tape. $Q_{\mathrm{g}}, Q_{\mathrm{gmax}}, Q_{\mathrm{gmin}}$ respectively are reactive power output of generator and its top and bottom limitation; $T \phi, T \phi$ max, $T \phi$ min are respectively the tap position value of transformer on-load voltage regulation tap and its top and bottom limitation; VD, VS, VDmax, Vgmax, VDmin, Vgmin are respectively node 


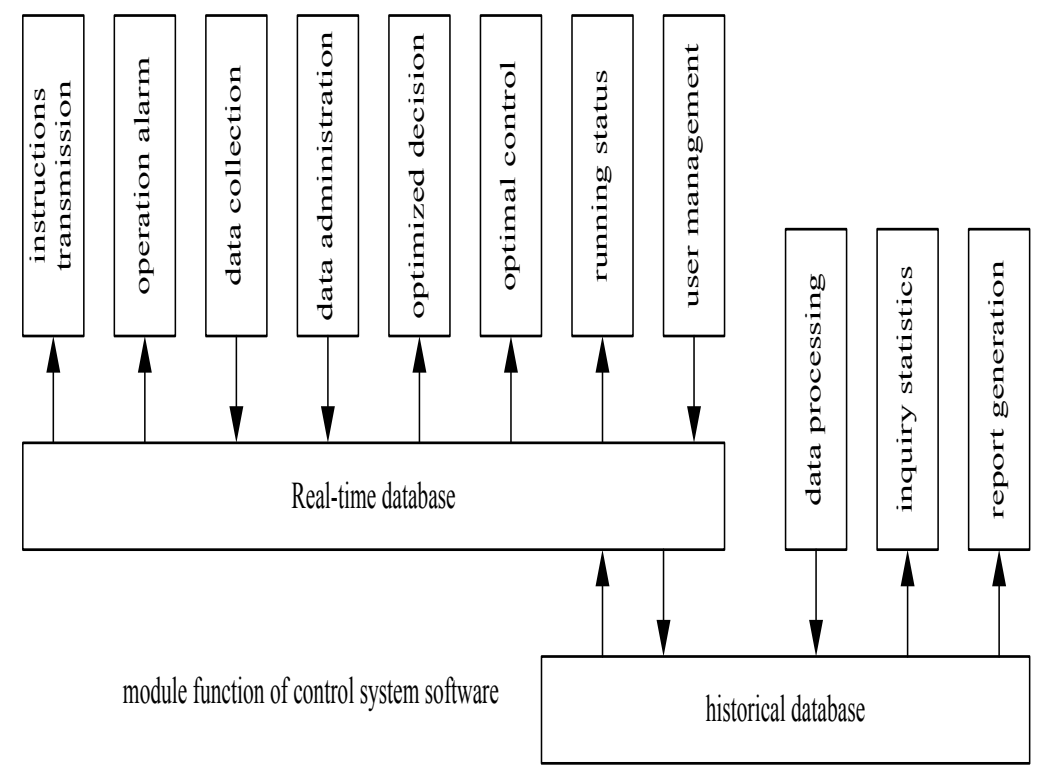

Fig. (3). The division of control system software module.

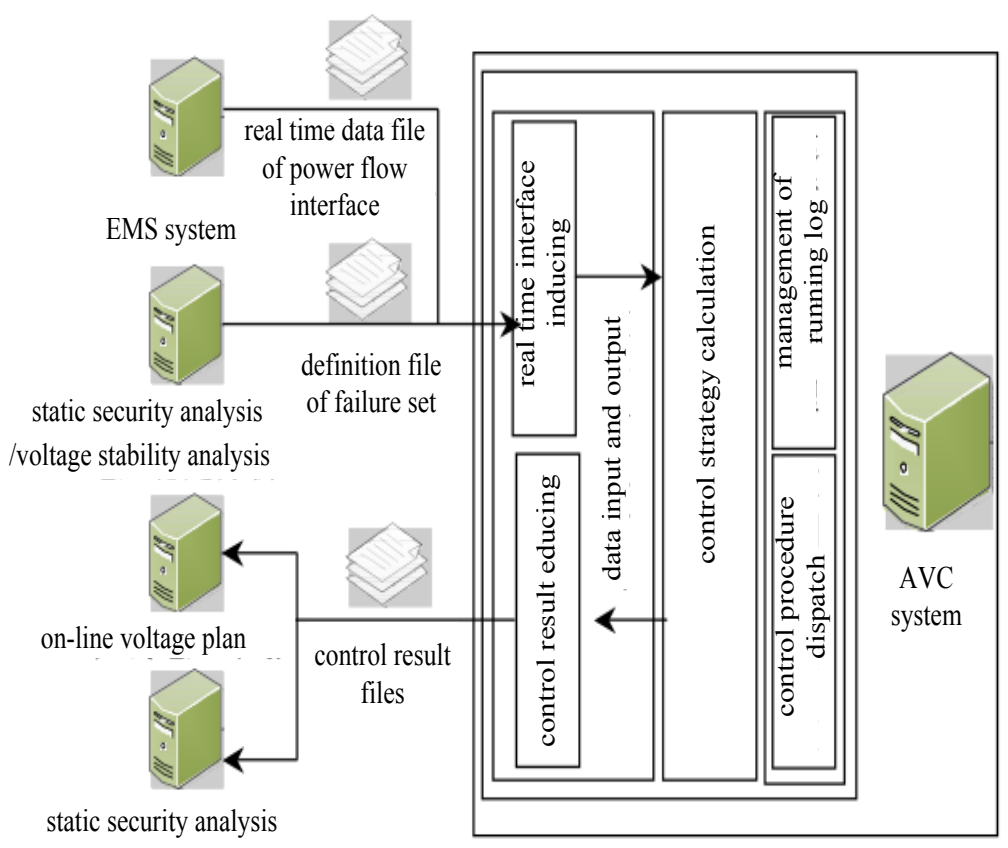

Fig. (4). The AVC system architecture.

voltage, generator terminal voltage value, and top \& bottom limitation.

\subsection{Application System Structure}

AVC system adopts the SCADA control system with standard communication protocol. Based on client/server of the $\mathrm{B} / \mathrm{S}$ software, the AVC system is a distributed architecture with dual server system. In the system hardware system, there are multiple 232, 485 and USB communication interfaces, forming a complete networking information interaction platform. VQC possesses the communication function of reactive power main station within the same region, receiving the given constant value of main station, and checking the constant value. Besides, when the main station is out of service, or when abnormal communications occur, VQC should be able to automatically switch to the local fixed value, and be able to upload, control, shut its own status information. The basic division of the control system software is shown in Fig. (3). The AVC system structure is as shown in Fig. (4) [11]. 


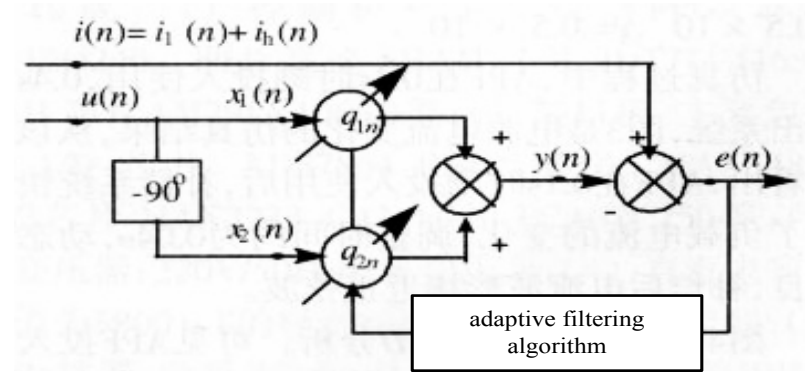

Fig. (5). Adaptive harmonic detection circuit principle diagram.

\section{ADAPTIVE STRATEGY OF HARMONIC SOURCE}

As the power grid in Wuhu region has the outstanding problem of having too many harmonics sources and high shock load of reactive power, a hybrid active power filter scheme which was made up of passive power filter and active power filter is adopted in voltage reactive power optimization schemes to deal with the damage of capacitor caused by the harmonic interference sources of system. This kind of filter is put forward mainly to overcome the disadvantages of active power filter used alone. Passive power filter is simple and practical and low cost, while active power filer has good compensation performance. The combination of them can bring high cost performance for the system.

\subsection{Adaptive Harmonic Detection Method}

Harmonic current detection is a key link of active power filter. The ip-iq detection method based on instantaneous reactive power theory has good real-time performance and it has been successfully applied in hybrid filter. A kind of adaptive harmonic detection circuit $[12,13]$ based on the principle of adaptive interference cancellation, as shown in Fig. (5).

In the figure, $\mathrm{u}(\mathrm{t})$ represents the voltage signal of power, and after passing through the filter, the voltage signal of power turns into the voltage signal of fundamental wave $u_{m} \sin \omega_{0} t$. Then, after $90^{\circ}$ phase shift, $R_{1}(t)=D \sin \omega_{0} t$ and $R_{2}(t)=D \cos \omega_{0} t$ appear. $i_{s}(t)$ is power side current. $i_{s f}(t)$ and $i_{s h}(t)$ respectively are power side fundamental wave current and harmonic current. If output $i_{0}(t)=i_{s f}(t)+i_{s h}(t)$, when $R_{1}(t), R_{2}(t)$ are multiplied by $i_{0}(t)$, the result will be that direct current signal be obtained only when the active component and reactive component of fundamental current in the $i_{0}(t)$ are respectively multiplied by $R_{1}(t)$ and $R_{2}(t)$ can, and if other signal multiply $R_{1}(t)$, $R_{2}(t)$ the result will be AC signal. Through periodical integration, the direct current signal obtained average value of fundamental active current $I_{F p}$ and the average value of fundamental reactive current $I_{F q}$. While, the result of AC

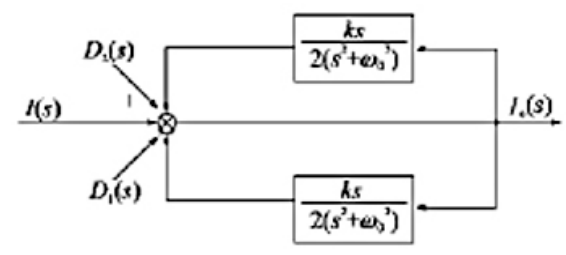

Fig. (6). The transfer function block diagram of the adaptive harmonic detection.

signal being periodically integrated is zero. If $I_{F p}$ and $I_{F q}$ respectively multiply $R_{1}(t), R_{2}(t)$, it can obtain the instantaneous fundamental active current $i_{f p}(t)$ and the instantaneous fundamental reactive current $i_{f q}(t)$. Subtracts is $(\mathrm{t})$ from feedback result of $i_{f p}(t)$ and $i_{f q}(t)$ to cancel out the $i_{s f}(t)$ of $i_{s}(t)$, thus it obtains the equation output $i_{0}(t)=$ $i_{s h}(t)$. The corresponding transfer function block diagram of Fig. (3) is as shown in Fig. (6);

As it can be seen in the figure, $\mathrm{D}_{1}(\mathrm{~s})$ and $\mathrm{D}_{2}(\mathrm{~s})$ cancel each other out.

The closed-loop amplitude-frequency characteristics of adaptive harmonic detection circuit.

$$
|\psi(j \omega)|=\frac{\omega_{0}^{2}-\omega^{2}}{\sqrt{\left(\omega_{0}^{2}-\omega^{2}\right)^{2}+(k \omega)^{2}}}
$$

As can be seen from equation (5), when $\omega=\omega_{0}$, $[\psi(j \omega)]=0$, it means that adaptive harmonic detection circuit generates infinite attenuation on power frequency fundamental component, thus the power frequency will shift and the system center frequency will also automatically adapt to the new state. And when $\omega>>\omega_{0}$ or $\omega<<\omega_{0}$ there will be $[\psi(j \omega)]=0$, and the harmonic can sweep through. Thus it can be seen that the Fig. (6) is an ideal adaptive harmonic detection system.

\subsection{System Constitution}

Fig. (7) is the schematic diagram of adaptive filtering system. The implemented LC filter includes three parts: five times, seven times, and high pass. The parameters are shown in Table $\mathbf{1 .}$

Table 1. LC filter parameters.

\begin{tabular}{|c|c|c|c|}
\hline Five Times & $L=1.2 m H$ & $C=340 \mu F$ & $Q=14$ \\
\hline \hline Seven times & $L=1.2 m H$ & $C=170 \mu F$ & $Q=14$ \\
\hline High pass filter & $L=0.26 m H$ & $C=300 \mu F$ & $R=3 \Omega$ \\
\hline
\end{tabular}




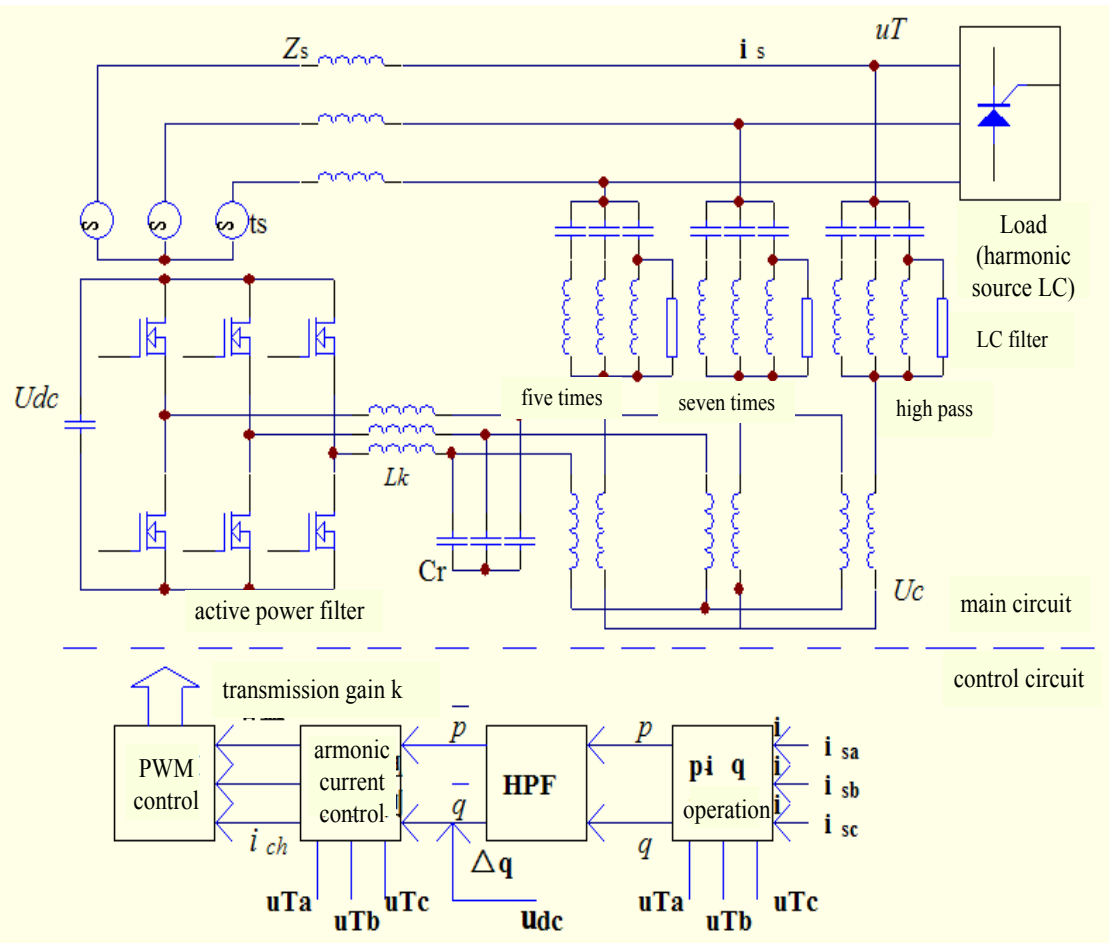

Fig. (7). Parallel active power filter with LC filter series hybrid system.

\section{ADAPTIVE TECHNOLOGY OF VOLTAGE REAC- TIVE POWER COMPLEX AUTOMATIC CONTROL SYSTEM(AVC)}

The control process of reactive power optimization automatic control system is shown in Fig. (8). The system firstly collects the real-time operation data of whole power grid from dispatch SCADA for the voltage and reactive power analysis, then it takes minimum power loss of whole power grid as objective function and adopts the methods like power flow calculation to repeatedly obtain second-best solution within the scope of minimum numerical value and calculate the action times of capacitor and main transformer tapchanger. When the action times reaches its minimum value, the corresponding solution is the optimal solution [14]. The AVC system, based on that, forms three kinds of instructions including the switch instruction of transformer substation capacitor, regulating instruction of main transformer tap, and economic operation instruction of multiple main transformer. All of these instructions will be executed by the dispatch center of power grid and the control system of SCADA monitoring center and that cycle repeats.

The operation and calculation process of reactive power optimization system as shown in Fig. (9).

\subsection{The Principles of Optimal Control}

Voltage and reactive power integrated control is to comprehensively regulate the voltage and reactive power of power substation through two distinguishing variable, voltage and reactive power, so as to keep the voltage within qualified range and realize the reactive power balance at the

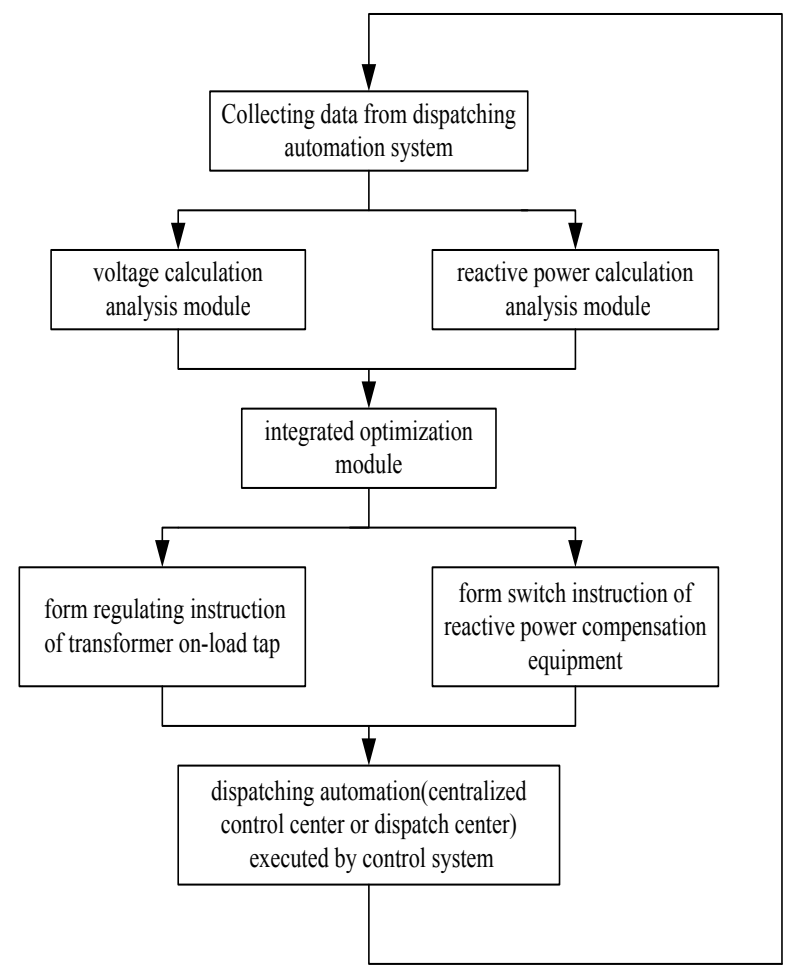

Fig. (8). Flow chart of automatic control system for reactive power optimization.

meantime. Voltage And reactive power integrated device has set up the bounds of voltage and reactive power, and divide the plane made up of voltage and reactive power into nine 


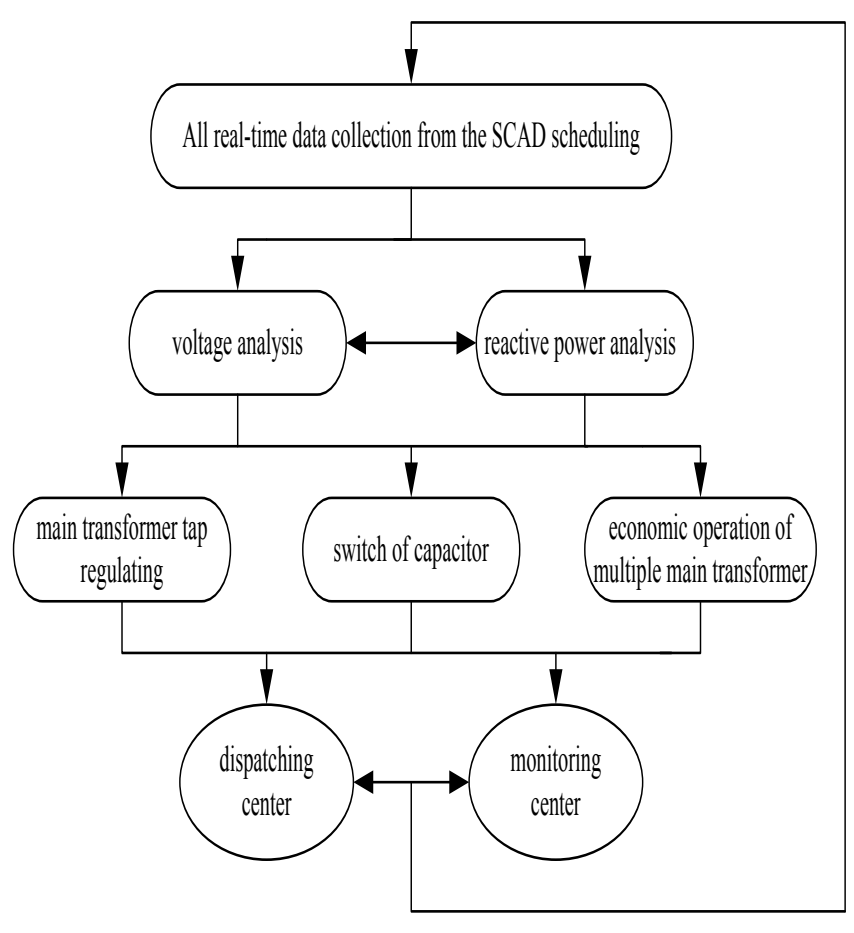

(a) software

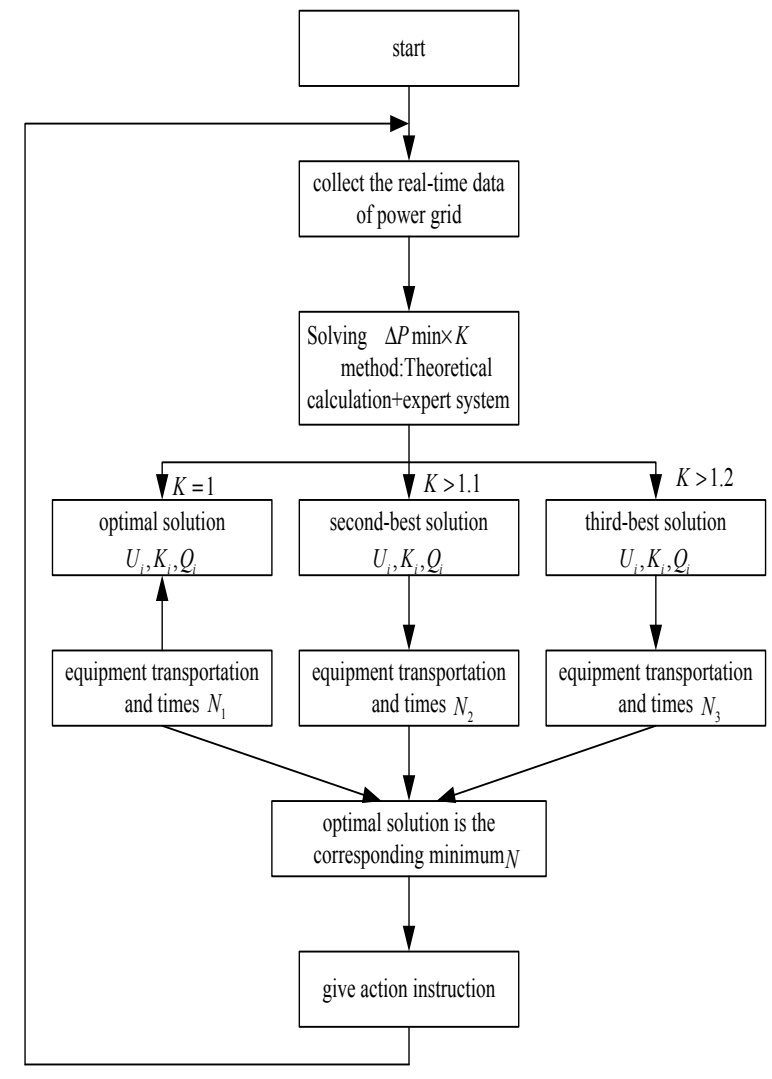

(b) calculation process

Fig. (9). Reactive power optimization of automatic control system and calculation flow chart of software logic.

domains, namely "jiugong diagram", as shown in Fig. (10) below. The bounds of voltage are set according to the acceptable voltage range, while the bounds of reactive power are based on the principles of keeping basic balance among each capacitance, capacitance deviation and reactive power, and keeping a relative balanced switch [15].

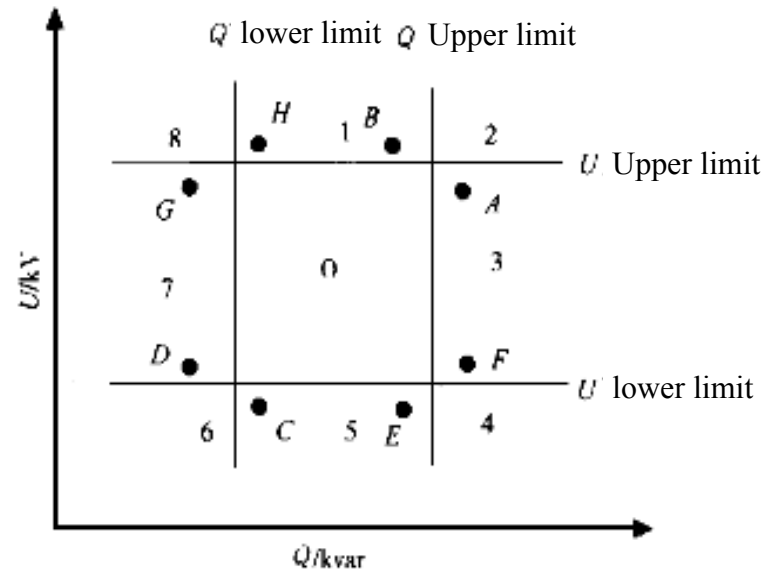

Fig. (10). Jiugong diagram.

\subsection{Control Objective}

The data acquisition of voltage, current, active and reactive power, power factor, main transformer gear of VQC device related node, and the location information collection of related circuit breaker, breaker, run/locking switch are conducted by the integrated automation system of substation, then the system conducts comprehensive control on main transformer tap switch and compensation capacitor bank according to 17 operation domains as shown in Fig. (11).

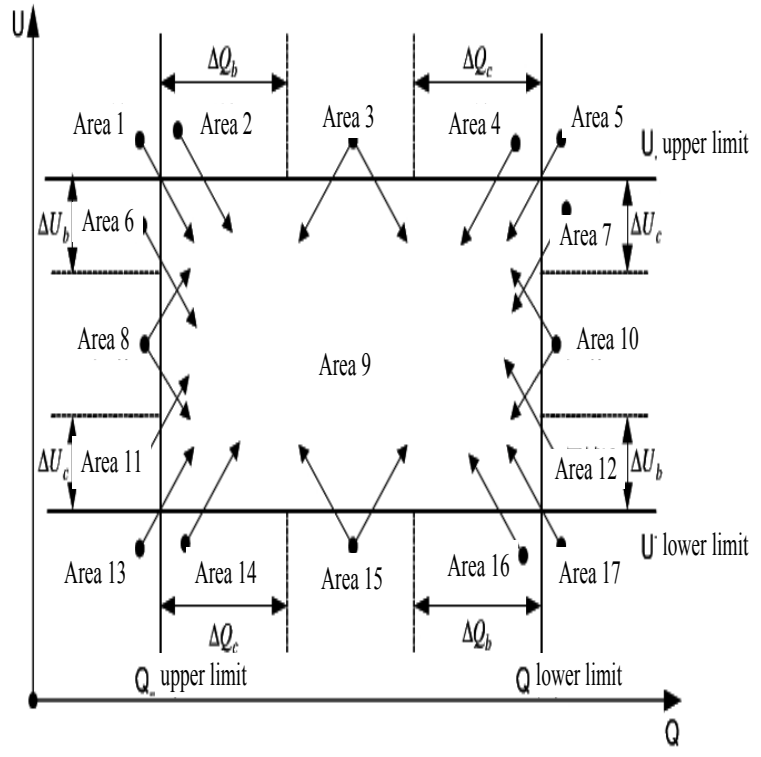

Fig. (11). 17 Area. 


\subsection{The Adaptive Strategy of AVC}

In the switching technology of capacity \& voltage regulated capacitor with auto-transformer integrated, the capacitor belongs to grouping adjustment of voltage regulation. The AVC interface with adaptive characteristics can achieve the following adjustment methods for each substation under the control of SCADA.

(1) Only regulating voltage

(2) Only regulating reactive power

(3) Voltage takes precedence (when voltage and reactive power can not be satisfied at the same time, voltage takes precedence).

(4) Reactive power takes precedence (when voltage and reactive power can not be satisfied at the same time, reactive power takes precedence).

(5) Intelligent adjustment (when voltage and reactive power can not be satisfied at the same time, reactive power takes precedence, maintain the same).

The external control state of the above AVC adaptive countermeasures is directly reflected as the overall optimal configuration of the grouping joint and capacity of capacitor switching, which can improve the voltage qualification rate and qualified rate of reactive power regulation. The adaptive countermeasures include the adaptive automatic control of signal blocking, closed loop, manual intervening half-closed loop. The results of AVC adaptive countermeasures can be real-timely displayed on the screen through the corresponding SCADA system.

\section{THE OPERATION PLATFORM OF SYSTEM AND THE APPLICATION SITUATION}

Since the application and practice of the voltage reactive power optimization automatic control system (AVC) in the Power Grid of Wuhu Region on July 1, 2013, the AVC system of the power grid in Wuhu region has been stable and reliable, which can be seen from the comparative analysis of energy management system of Anhui electric power company about the operation condition of the system before and after operation; The system has significantly reduced the action times of equipment, thus improving the voltage qualified rate and power factor of the $220 \mathrm{kv}, 110 \mathrm{kv}$ busbar in the power grid $\backslash$ and bringing obvious efficiency.

\subsection{Analysis of Loss Reduction Effect}

In the second half of 2013 the network loss rate was $1.82 \%$, and $0.36 \%$ year-on-year decrease, saving 720000 kilowatt. As shown in Table 2.

Table 2. Yi jiang area loss reduction effect of statistical analysis (10 x 5 kwh).

\begin{tabular}{|c|c|c|c|c|}
\hline Year & $\begin{array}{c}\text { Statistical } \\
\text { Time }\end{array}$ & $\begin{array}{c}\text { Power } \\
\text { Supply } \\
\text { Quantity }\end{array}$ & $\begin{array}{c}\text { Power } \\
\text { Loss } \\
\text { Quantity }\end{array}$ & $\begin{array}{c}\text { Line Loss } \\
\text { Per Unit\% }\end{array}$ \\
\hline \hline 2013 & $7-12$ month & 21107 & 365 & 1.82 \\
\hline 2012 & $7-12$ month & 17136 & 216 & 2.18 \\
\hline
\end{tabular}

\subsection{The Analysis of Improving Voltage Qualified Rate}

After the application of AVC system, the voltage qualified rate of $220 \mathrm{kv}, 110 \mathrm{kv}, 35 \mathrm{kv}$ in the precinct are all within the scope of index control of the company. Among them, Table $\mathbf{3}$ is a analysis table showing the qualified rate of busbar voltage after AVC system being put into operation between July 2013 and December 2013 (compared with the same period in 2012).

Table 3. AVC after operation of busbar voltage qualified rate analysis.

\begin{tabular}{|c|c|c|c|}
\hline Busbar Level & $\begin{array}{c}\text { Qualified } \\
\text { Rate Before } \\
\text { Application }\end{array}$ & $\begin{array}{c}\text { Qualified } \\
\text { Rate After } \\
\text { Application }\end{array}$ & $\begin{array}{c}\text { Year-On- } \\
\text { Year } \\
\text { Growth }\end{array}$ \\
\hline \hline $220 \mathrm{kV}$ & $86.57 \%$ & $99.95 \%$ & $13.38 \%$ \\
\hline $110 \mathrm{kV}$ & $98.50 \%$ & $99.98 \%$ & $1.48 \%$ \\
\hline $35 \mathrm{kV}$ & $99.74 \%$ & $99.96 \%$ & $0.22 \%$ \\
\hline
\end{tabular}

\subsection{The action times of equipment}

An obvious decrease on the action times of equipment after the application of system. Table (4) is the statistics table of average daily action times of the equipment in Yejiang district.

Table 4. Equipment daily average number statistics table.

\begin{tabular}{|c|c|c|c|}
\hline $\begin{array}{c}\text { Classification of } \\
\text { Control Equipment }\end{array}$ & $\begin{array}{c}\text { First Half Year } \\
\text { of 2013 }\end{array}$ & $\begin{array}{c}\text { Next Half } \\
\text { Year of } \\
\mathbf{2 0 1 3}\end{array}$ & $\begin{array}{c}\text { Reducing } \\
\text { Rate (\%) }\end{array}$ \\
\hline \hline $\begin{array}{c}\text { average daily action } \\
\text { times of capacitor }\end{array}$ & 36 & 32 & 11.11 \\
\hline $\begin{array}{c}\text { average daily action } \\
\text { times of main trans- } \\
\text { former gear }\end{array}$ & 47 & 41 & 12.7 \\
\hline
\end{tabular}

\subsection{Improvement of Power Factor}

The improvement of the power factor of $35 \mathrm{kv}$ transformer substation in Yejiang district in the second half of 2013 is shown in Table $\mathbf{5}$.

Table 5. In the second quarter of 2013 qualified rate statistical reactive interface power factor.

\begin{tabular}{|c|c|c|c|}
\hline Year Qualified Rate & Peak & Valley & $\begin{array}{c}\text { Normal } \\
\text { Times }\end{array}$ \\
\hline \hline 2013 qualified rate (\%) & 96.76 & 95.74 & 98.37 \\
\hline 2012 qualified rate (\%) & 89.45 & 94.09 & 94.33 \\
\hline year-on-year (\%) & 7.13 & 1.65 & 4.04 \\
\hline
\end{tabular}




\subsection{The Analysis of Resisting Harmonic Interference}

Use MT1010 Electricity harmonic tester to test the power demand side of substation, power supply terminal and signal end of SCADA system, and the results all accord with the standard of the national GB/T14549-93 power quality and harmonics in public supply network.

\section{CONCLUSION}

Adopting the mode of centralized decision-making, multilevel coordination, hierarchical distributed control of the AVC System, Wuhu power grid has successfully solved the problem of harmonic interference, changed the situation of low degree of automation, low efficiency and high working strength in the power grid of Wuhu region, and formed a set of complete real-time automatic control system with adaptive ability. With the development of interconnected power grid, the advancement of smart grid construction, and the application of AVC system at at all levels of power grid, the reactive voltage optimization control is no more limited in local region, but need the regulation from multistage power grid and between coordinates different regions. But the mismatch problem between each other is increasingly prominent [16-18], thus how to solve the problem of different control targets, control requirements and control ability is the emphasis needs further research in the future.

\section{CONFLICT OF INTEREST}

The authors confirm that this article content has no conflicts of interest.

\section{ACKNOWLEDGEMENTS}

Declared none.

\section{REFERENCES}

[1] Y. Zhang, Z. Ren, and B. Li, "Survey on optimal reactive power dispatch of power systems," Power System Technology, vol. 29, no. 2, pp. 50-56, 2005.
[2] H.M. Ma, and K.T. Mmanf, "Multiobjective coordinated power voltage control using jumping genes paradigm," IEEE Trans on Industrial Electronics, vol. 55, no. 11, pp. 4075-4084, 2008.

[3] Y. Zhang, C. Chen, Y. Li, and G. Wu, "Dynamic voltage support planning for receiving end power systems based on evaluation of state separating and transferring risks," Electric Power Systems Research, vol. 80, no. 12 , pp. 1520-1527, 2010.

[4] D. Li, S. Chen, D. Wu, S. Jiang, and W. Tang, "The Design and Implementation of Anhui Power Grid Automatic Voltage Control (AVC) System," Automation of Electric Power System, vol. 28, no, 8, pp. 20-22, 2004.

[5] S Wang, "Discussion on Smart Grid Voltage and Reactive Power Automatic Control AVC System," Technology and Market, vol. 19 , no. 5 , pp. $60-61,2012$.

[6] Z. Wang, "Harmonic elimination and reactive power compensation," Beijing Mechanic industry Press, 1998.

[7] Q. Yin, "A County Regional Grid Voltage and Reactive Power Automatic Control System Design," Sichuan Electric Power Technology, vol. 29, no. 4, pp. 55-58, 2006.

[8] X. Ding, L. Zhou, and G. Chen, "Automatic voltage control (AVC) technology and the case analysis of," Mechanical Industry Press, 2010

[9] Z. Yan, "A new algorithm of optimal power flow," Beijing: Tsinghua University, 1991.

[10] S. Wang, Y. Yuan, and L. Lu, "The Research of Hybrid Power Filter Based on Adaptive Harmonic Detection," Electric Drive, vol. 30 , no. 1, pp. 60-62, 2000.

[11] M. Zhang, Q. Guo, H. Sun, J. Tong, B. Zhang, W. Wu, and B. Wang, "Design and Implementation of Automatic Voltage Control System Applied to a Power Grid in Northeast US," Power Syetem Technology, vol. 37, no. 2, pp. 349-355, 2013.

[12] Z. Wang, "Harmonic elimination and reactive power compensation (The second edition)," Beijing: Machinery Industry Press, 2006.

[13] X. Xie, J. Liao, L. Zheng, and J. Yin, "Active Power Filter Based on Improved Adaptive Harmonic Detection," Electrical Measurement \& Instrumentation, vol. 49, no. 4, pp. 42-46, 2012.

[14] C. Wang, W. Gong, X. Duan, and S. Wang, "Influence of reactive voltage optimization and centralized control systems on power grids," East China Electric Power, vol. 35, no. 9, pp. 42-46, 2007.

[15] Y. Guo, "Analysis of Voltage Reactive Power Automatic Control System," Electronics World, vol. 13, pp. 29-30, 2011.

[16] Y. Zhang, J. Lin, and Y. Yang, "Multi-level Voltage Control Mismatch of Large Scale Power Grids and Its Game Modeling," Automation of Electric Power System, vol. 35, no. 21, pp. 34-39, 2011.

[17] Y. Zhang, J. Lin, and Y. Yang, "Survey on Voltage/Var Control and Coordination of Power Systems," Power System Technology, vol. 36, no. 3, pp. 101-107, 2012.

[18] J. Li, J. Lin, G. Wu, Y. Zhang, Z. Cai, and Y. Yang, "Mechanism of Voltage Control Mismatch Between Provincial Power Grid and Regional Power Network and Its Three-Dimensional Analysis," Power System Technology, vol. 37, no. 5, pp. 1395-1400, 2013.

Received: June 02, 2015

(C) Liang et al.; Licensee Bentham Open.

This is an open access article licensed under the terms of the Creative Commons Attribution Non-Commercial License (http://creativecommons.org/licenses/by$\mathrm{nc} / 3.0 /$ ) which permits unrestricted, non-commercial use, distribution and reproduction in any medium, provided the work is properly cited. 